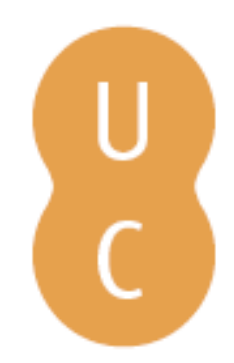

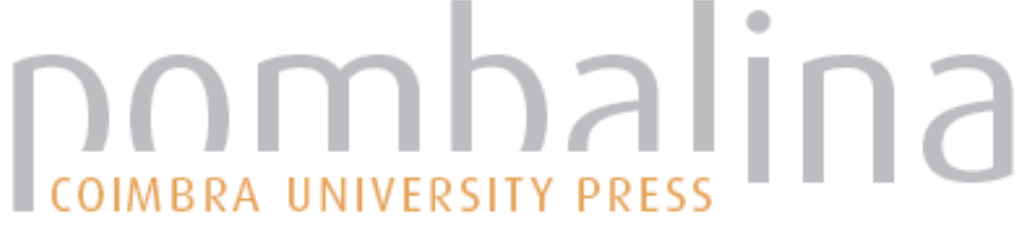

\section{O Geógrafo e o seu labirinto: António Gama, uma Geografia vivida}

\author{
Autor(es): Jacinto, Rui \\ Publicado por: Imprensa da Universidade de Coimbra \\ URL \\ persistente: URI:http://hdl.handle.net/10316.2/43474 \\ DOI: $\quad$ DOl:https://doi.org/10.14195/978-989-26-1343-7_4
}

Accessed : $\quad$ 26-Apr-2023 15:19:06

A navegação consulta e descarregamento dos títulos inseridos nas Bibliotecas Digitais UC Digitalis, UC Pombalina e UC Impactum, pressupõem a aceitação plena e sem reservas dos Termos e Condições de Uso destas Bibliotecas Digitais, disponíveis em https://digitalis.uc.pt/pt-pt/termos.

Conforme exposto nos referidos Termos e Condições de Uso, o descarregamento de títulos de acesso restrito requer uma licença válida de autorização devendo o utilizador aceder ao(s) documento(s) a partir de um endereço de IP da instituição detentora da supramencionada licença.

Ao utilizador é apenas permitido o descarregamento para uso pessoal, pelo que o emprego do(s) título(s) descarregado(s) para outro fim, designadamente comercial, carece de autorização do respetivo autor ou editor da obra.

Na medida em que todas as obras da UC Digitalis se encontram protegidas pelo Código do Direito de Autor e Direitos Conexos e demais legislação aplicável, toda a cópia, parcial ou total, deste documento, nos casos em que é legalmente admitida, deverá conter ou fazer-se acompanhar por este aviso.

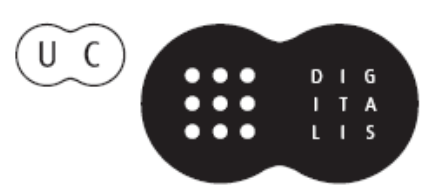




\section{FERNANDA CRAVIDÃO}

\section{IÚCIO CUNHA}

PAULA SANTANA

\section{NORBERTOSANTOS}

(ORG.)

\section{ESPAÇOS E TEMPOS EM GEOGRAFIA}

HOMENAGEM A ANTÓNIO GAMA

IMPRENISA DÁ UNIVERSIDADE DE COIMBRA COIMBRA UNIVERSITY PRESS

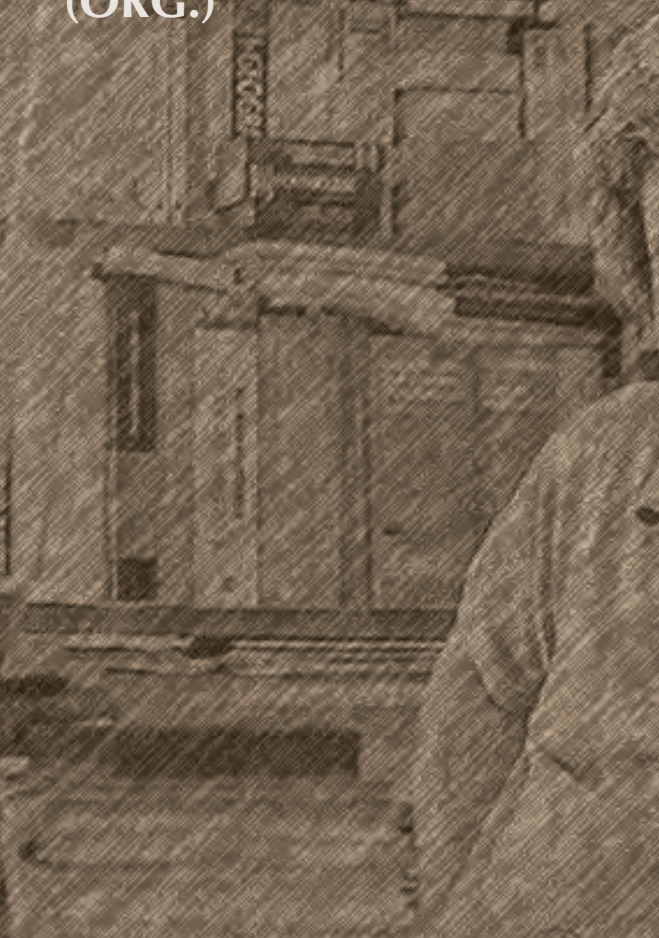




\title{
O GEÓGRAFO E O SEU LABIRINTO: ANTÓNIO GAMA, UMA GEOGRAFIA VIVIDA
}

\author{
Rui Jacinto/rui.jacinto@iol.pt \\ Centro de Estudos de Geografia e Ordenamento do Território \\ e Departamento de Geografia e Turismo \\ da Faculdade de Letras da Universidade de Coimbra
}

Retalhos de uma vida vivida: um olhar íntimo, uma narrativa pessoal

"O vivido intensivo dos lugares apaga-se definitivamente perante o vivido fragmentado saltitando por entre náo lugares" (AG, 2008).

O convívio de quatro décadas que mantive com António Gama Mendes, além de pessoalmente gratificante, foi profundamente enriquecedor em termos científicos e profissionais. O nosso primeiro encontro remonta ao final de 1972 quando numa aula prática de Geografia Física do primeiro ano da Universidade, onde era monitor, me distribuiu um mapa onde estava representado um troço do Rio dos Mouros, para fazer o respetivo perfil longitudinal. O tempo havia de provar que não foi o facto de estar perante um território que correspondia ao meu espaço vivido que gerou uma empatia imediata e espontânea, mas a sua capacidade de relacionamento e a disponibilidade genuína para apoiar e orientar quem dele se abeirasse.

Não sabia ainda que António Gama estava a investigar os Tufos de Condeixa, no âmbito da sua dissertação de licenciatura, cuja evoluçáo (geo)morfológica 
se deve, em boa medida, àquele afluente do Mondego, oriundo das Serras calcárias de Sicó, que recebeu a denominação excessiva de Rio apesar de, durante quase todo o ano, não correr o mais leve fio de água no seu leito. Havíamos de calcorrear as suas margens em vários sentidos, naquele âmbito, noutras circunstâncias ou durante a preparaçáo do seminário de fim de curso onde haveria de estudar o dito Rio dos Mouros. Entre estes momentos iniciais e os anos de brasa subsequentes ao 25 de Abril decorreu um tempo breve mas suficiente para se esboçar uma cumplicidade duradoura de que continuo a reter gratas e indeléveis recordaçôes. Pontuam-na conversas ao acaso, enquanto se caminhava sem destino aparente, debates acalorados, sem tempo nem agenda, em lugares inesperados e improváveis, fossem os corredores da Faculdade, os Jardins da Associação Académica, os cafés, tabernas ou casas de pasto da Baixa.

António Gama tinha facilidade em congregar pessoas à sua volta, gerar um ambiente descontraído e informal, porventura utópico, portanto, propício ao esboço de estratégias infalíveis, nem sempre concretizadas, onde se carpiam derrotas futebolísticas, faziam catarses políticas e pessoais, comemoravam alguns sucessos, mas, sobretudo, as inúmeras vitórias morais que se iam alcançando. A omnipresença da Geografia nunca limitou as conversas nem circunscreveu os debates ao seu perímetro restrito, pois fluíam ao sabor das circunstâncias e dos banais acontecimentos quotidianos, que alimentam a espuma dos dias, comentavam-se as táticas do futebol, a política corriqueira ou a mudança na geopolítica global imposta pelos novos e emergentes realinhamentos. Neste círculo os livros tinham lugar cativo, eram presença obrigatória, tutelar e estimulante, onde se inspirava para nos provocar, sonhar novos projetos, tantas vezes adiados, idealizar viagens, nem sempre concretizadas.

O desejo de mudança conjugado com o espírito inovador e de contida irreverência alcandoraram António Gama a referência incontornável da minha geração e dos que, nas décadas seguintes, haviam de frequentar a Geografia de Coimbra. Divulgador científico e agitador de consciências, aliou voluntarismo, disponibilidade e proximidade aos estudantes com um toque de sonho e ingenuidade típicos duma época e duma juventude comprometida. A procura de novos rumos para a vida e para a sociedade também passava por superar 
os apertados limites onde se movia a Geografia. Apostou em encontrar novas abordagens teóricas e práticas, conceituais e metodológicas, emprestou a sua atitude e olhar crítico a um processo de renovaçáo onde teve um envolvimento ativo e destacado. Os pressupostos do seu empenho neste processo de renovação curricular, pedagógica e da investigação deixou-os assim resumidos: "as transformações políticas desencadeadas pela Revolução de 1974, abriram novas possibilidades e novos horizontes no âmbito da universidade e a que os estudos da Geografia também não ficaram indiferentes. Novos planos de estudos, com novos curricula, mais actualizados em linha com o que se fazia em França mas também no mundo anglo-saxónico, até então quase ignorado nas matérias versadas" (Gama, 2011: 240).

Esta "fase de juventude" foi de combate por uma "nova geografia", marcada pela informalidade, modo de estar que encaixava num perfil avesso a institucionalizaçóes. António Gama foi precursor de abertura e diálogo com outras geografias, espaciais e disciplinares, visando superar debilidades e esbater as limitadas "fronteiras" disciplinares e conimbricenses, iniciando um processo que hoje designaríamos de “internacionalização". Tentou alargar horizontes e esbater fronteiras, quase sempre artificiais, como as que separam disciplinas científicas e impedem um conhecimento mais holístico. Construiu pontes que permitiram alargar horizontes abertos a outras práticas e novas perspetivas de que todos nós acabaríamos por beneficiar.

Continua ainda bem presente na memória uma deslocação a Lisboa, no início de Maio de 1974, com outros colegas, em representação da Geografia de Coimbra, para participar numa reunião no Centro de Estudos Geográficos de Lisboa, onde se proporcionou um primeiro contacto direto com o Professor Jorge Gaspar e João Ferrão que havia de ter múltiplas consequências positivas. Nos anos imediatos, Jorge Gaspar havia de orientar duas memoráveis viagens de estudo, organizadas por António Gama, à Área Metropolitana de Lisboa e à Área de Influência de Évora. Esta abertura estendeu-se a Salamanca e a Léon, proporcionou amizades que se consolidaram nos Congressos Ibéricos de Geografia e, não menos importante, durante os primeiros Acampamentos Nacionais de Geografia. Este último evento, onde participou militantemente 
durante vários anos, facultava o diálogo direto entre professores e alunos, provenientes das diferentes escolas de Geografia entáo existentes em Portugal (Lisboa, Coimbra e, na terceira edição, Porto), verdadeira plataforma informal e inter-geracional, antecipando os moldes em que se concebem, hoje, os festivais de diferentes matizes.

Desses tempos primordiais recordo ainda a participação dum grupo de alunos de Geografia, recrutados por António Gama, num Inquérito de Sociologia Política, coordenado pelo Professor Boaventura Sousa Santos, realizado em 22 e 23 de Abril de 1975, nas vésperas das primeiras eleiçóes livres, depois da Revolução de Abril. Superar as fronteiras disciplinares, ir além do perímetro da geografia, onde já estava satisfatoriamente instalado, para dialogar com outros saberes, levou-o a sair da sua área de conforto, percorrer caminhos incertos e cumprir certos rituais que asseguram a passagem para um outro estádio.

O carácter pessoal e, portanto, subjetivo desta narrativa desculpa outras referências íntimas onde cabem múltiplas viagens. Foram importantes algumas caminhadas, durante o trabalho de campo, ao redor de Condeixa, estudando os tufos e as serras calcárias, ou as que se prolongavam até à paragem do autocarro, depois das prazerosas conversas de fim tarde, quando passamos a partilhar o mesmo gabinete. Este ciclo havia de se fechar com as viagens de estudo que passou a orientar nos Cursos de Veráo, organizado pelo Centro de Estudos Ibéricos, e a grande viagem que se augurou definitiva, efetuada a Cabo Verde em 2011. A tudo isto acresce um episódio que havia de marcar profundamente a minha história de vida, pois ditou o meu percurso profissional: foi António Gama quem sugeriu o meu nome a Ana Pires, em janeiro de 1976, que lhe havia solicitado a indicaçáo de estudantes para colaborarem, supostamente em regime de voluntariado, em tarefas da Comissão de Planeamento da Regiáo Centro. Depois da primeira grande crise financeira do período democrático ter gorado a nossa entrada como monitor, acabei tarefeiro, por esta via informal, numa instituição onde continuo a trabalhar. A dívida de gratidão que resulta deste gesto, generoso e desinteressado, é impossível de ser saldada.

O longo percurso que medeia entre estes momentos matriciais e a sua retirada, no início da segunda década do século Xxi, teve altos e baixos, oscilou entre 
o fulgor criativo e irreverente da "fase de juventude" e o confronto com uma dura "fase de maturidade", que se foi impondo, paulatinamente, a partir dos anos 80. Abstraindo afetos e emoçóes, a real dimensão do contributo material e intangível de António Gama só se apreende cabalmente se remontarmos a esse período mais recuado onde se refugia esta evocação. Ao resgatar da poeira do tempo a memória desse período irrepetível e empolgante prevalece uma entrega que, apesar dos elevados custos pessoais, foi total e sem concessốes ou subterfúgios onde se escondesse alguma expectativa de retorno pessoal. A permanente insatisfação pela perfeição e a escrupulosa obsessão pelo rigor, teórico e prático, haviam de colocar constrangimentos à caminhada promissora dum protagonista crítico, cuja voz se impôs pela qualidade da intervenção num momento de viragem na história da Geografia portuguesa e de Coimbra.

\section{Geografia de um legado: tempo, temas, contextos}

"Anos agitados e de agitação de ideias, numa entusiasmada $e$ entusiasmante procura de caminhos novos. Umas vezes de comum acordo, outras a contra corrente, as mudanças foram-se processando" (AG, 2011).

As incursões já efetuadas pelos meandros da memória, da que realmente nos cerca e da que nos tentam impor, para tentar esboçar o perfil e o papel de António Gama na renovação da investigação e do ensino da Geografia, realçaram a importância do investigador inovador, voluntarista e empenhado que esta breve síntese resume: "o Gama esteve sempre pronto a ajudar no aprofundamento de um conceito, nos caminhos possíveis para uma pesquisa, na facilitação do acesso às bibliografias, mesmo quando isso significava o gasto do seu tempo que tanta falta lhe fazia, como a diminuição da eficácia nas suas tarefas de docente e investigador, ou seja, a "carreira"” (Jorge Gaspar, 2015). Assinalaram que estamos perante um "heterodoxo inconformado" que cultivou um "pensamento crítico e integrador" que olhava com desconfiança 
para "a híper especialização acrítica que viu alastrar à sua volta” (Jacinto et al., 2015); acreditava "numa geografia grandiosa, sem um perímetro bem delimitado", como atesta "um conjunto de ensaios muito valiosos, nalguns casos pioneiros", "reflexóes de grande atualidade sobre os fenómenos sociais vinculados ao território, à urbanização difusa e ao uso do tempo" (João Ferrão, 2015).

"Professor sem fronteiras disciplinares", "sem amarras dogmáticas”, estava consciente que os temas e os problemas estão "cada vez mais imbricados e interdependentes sob o signo da interdisciplinaridade e da complementaridade" (Valentin Cabero, 2016). As suas intervençôes transcendiam-se no terreno "onde verbaliza mapas que permitiam ler e interpretar, para além das aparências, as paisagens físicas, económicas, sociais, culturais e políticas que desfilavam diante dos nossos olhos; o lugar onde falava era o ponto de partida duma interminável viagem que transcendia fronteiras, geográficas e disciplinares, e nos projetava para dimensôes mais elevadas, intangíveis e globais” (Rui Jacinto, 2016).

O retrato traçado atesta a importância dum legado, eclético e abrangente, que não se pode resumir, exclusivamente, à obra publicada. $\mathrm{O}$ seu impulso inovador, embora tenha eco nos textos que vieram a lume, não se esgotou na palavra escrita, pois a sua influência foi derramada em palavras seminais escutadas, ao longo dos anos, por alunos, colegas e amigos. A oralidade tem que ser enaltecida como uma parte significativa do património mais intangível de António Gama, indissociável duma atividade pedagógica que extravasou as paredes das salas de aula, sobretudo durante as viagens de estudo e o trabalho de campo, que entendia como um laboratório natural para o ensino da Geografia. Sem resiliência nem paciência para seguir normas estritas ou obedecer a uma tecnocracia que se esgota, tantas vezes, na aridez inconsequente de estatísticas ou em exercícios e técnicas analíticas, privilegiou a palavra, os livros e a teoria em detrimento de abordagens positivistas e empíricas, opção que o havia de penalizar em termos académicos.

António Gama foi um geógrafo comprometido, cujos contornos do seu legado e alicerces teóricos do seu pensamento geográfico só se conseguem abranger a partir da influência que recebeu por via dos mestres, dos livros e autores de 
referência. Aos mestres, mais ou menos próximos, com quem conviveu numa relação nem sempre pacífica, prestou tributo quando lhes dedicou ensaios e reflexóes nos respetivos livros de homenagem, produzindo reflexóes que, curiosamente, são em torno da teoria da geografia: Orlando Ribeiro (Geografia e Civilização, 1981), José Manuel Pereira de Oliveira (Escalas, Representação e Acçâo Social, 1998); Alfredo Fernandes Martins (Geografia, conhecimento do espaço e cidadania, 2003), Jorge Gaspar (Uma revisitação à time space geography: A geografia do tempo e a teoria social, 2007), Fernando Rebelo (A geomorfologia, entre a geologia e a geografia: um problema de identidade, 2010, em colaboração com Luca A. Dimuccio).

Os autores de referência, de culto, que citava amiúde e de memória, estão plasmados nas longas, criteriosas e assertivas bibliografias que incluiu nos seus artigos, haviam de constituir o núcleo duro duma biblioteca ímpar, pela dimensão, diversidade e qualidade do espólio. Os livros eram uma paixão para António Gama e a sua biblioteca um universo invulgar, que construiu laboriosamente ao longo da vida, reflexo do seu modo de olhar e estar no mundo, do entendimento que fazia da geografia e de ser geógrafo. Tinha prazer em oferecer livros, distribuir fotocópias de artigos, sobretudo novidades a que estava sempre atento. Foi um divulgador incansável dos debates mais atuais, das controvérsias mais estimulantes, das reflexóes mais inovadoras: quando surgiu a "Hérodote. Revue de géographie et de géopolitique”, em 1976, abrindo o debate premonitório "Crise de la géographie, géographie de la crise", já António Gama havia antecipado esta interrogação, suscitando a discussão deste e doutros temas, igualmente controversos, que o léxico atual apelidaria de fraturantes.

O acompanhamento detalhado dos acontecimentos da geografia francesa, de que era profundo conhecedor, ficou documentado na atenção imediata que deu a dois livros publicados em 1976: "A geografia serve antes de mais para fazer a guerra" (Yves Lacoste), traduzido e editado pela Iniciativas Editoriais (1977), a que dedicou, prontamente, uma recensáo no primeiro número da Revista Critica de Ciências Sociais (Em torno da Geografia serve antes para fazer a Guerra, 1978); "La Région, Espace Vécu", de Armando Fremont, surgido no mesmo 
ano, cuja tradução havia de sugerir à Almedina, fazendo a revisão, editada em 1980. Com Jorge Gaspar promoveu ainda a edição de Paul Claval, compilando textos deste autor (Geografia do Homem, 1987), igualmente publicada com a chancela da Almedina.

A sua atenção, contudo, nunca se confinou à geografia francesa. Observando a longa lista de referências bibliográficas (25 títulos) que incluíu em "Uma revisitação à time space geography” (2007), com que homenageou Jorge Gaspar, verificamos que os autores citados são todos anglo-saxónicos, com destaque para Hagerstrand (5 citaçôes), com quem Jorge Gaspar havia investigado em Lund, além de Gregory (7), Giddens e Pred (3 cada), outros dos seus autores de cabeceira. Além dos marxistas (David Harvey, por exemplo), a sua atenção à escola anglo-saxónica é igualmente visível quando faz uma extensa recensão ao "Geografical Imaginations" (Derek Gregory; B. Blackwell, Oxford, 1994), publicada no ano imediato à sua edição, na Infor Geo, Revista da Associação Portuguesa de Geógrafos (n. os 9 e 10, 1995).

Explorou outras fronteiras, valorizou geógrafos ignorados ou marginalizados pela geografia oficial, deu a conhecer, por exemplo, Camille Vallaux, preterido em detrimento de Emanuel de Martonne, genro de Vidal de la Blache e que havia de editar, postumamente, a sua obra mais difundida entre nós (Principios de Geografia Humana), brilhantemente traduzida, prefaciada e ilustrada por Alfredo Fernandes Martins. Este diálogo estendeu-se a outros subalternizados, designadamente os anarquistas, testemunhado em dois números temáticos de $A$ Ideia $(24-25$ e 26-27, 1982), onde publicou “ $O$ pensamento de Réclus e as cidades", na que discutiu "A cidade ingovernável?", ou quando discorreu sobre "A aldeia e a vida camponesa", na que debateu " $O$ Campo e os Camponeses".

A sua paixão pela obra de Milton Santos aumentou nos últimos anos, com mais afinco desde que "em fevereiro de 2010, a Fundação Coordenação de Aperfeiçoamento de Pessoal de Nível Superior - CAPES e a Universidade de Coimbra, por intermédio do Centro de Estudos Sociais, estabeleceram o programa "Cátedra Milton Santos", com o intuito principal de contribuir para a difusão de informaçóes objetivas sobre a dinâmica da sociedade brasileira em 
centros universitários de excelência no exterior" ${ }^{1}$. Julgo tratar-se do último verdadeiro combate que travou, solitário, íntimo e magoado, sem nunca explicitar ou emitir qualquer rumor. Ainda em julho de 2014, durante o Curso de Verão, em conversa com Maria Adélia de Souza, amiga e confidente de Milton, tentava perceber alguns meandros pessoais e políticos da sua trajetória para melhor enquadrar as análises críticas deste autor.

António Gama personificou a transição ocorrida na Geografia de Coimbra depois de 1974. A sua tese de licenciatura, a última a ser defendida, em 1974, já depois do 25 de Abril, fecha um ciclo, encerra uma longa etapa, que se iniciou no final dos anos trinta, que se traduziu na apresentação de mais de uma centena de teses de licenciatura em Geografia, apresentadas em Coimbra. Por sua vez, a entrada como assistente e o seu envolvimento naquele processo, como já foi aduzido, inscreve-se no início duma nova era que então começa a despontar.

A dificuldade em se submeter a calendários rígidos não o impediu de participar em vários projetos de investigação, a começar pelas iniciativas que, informalmente, dinamizou com colegas e alunos, baseadas no espírito de partilha e em redes interpessoais, processo que se vai esvanecer com o tempo e causar alguma amargura pessoal ao comandante que vê as tropas irem desertando. Começa a encetar, no entanto, múltiplas colaboraçôes que redundam na publicação de trabalhos, alguns em coautoria com diversos colegas, além de cooperar em vários projetos de investigação com distintas personalidades e vários centros de investigação.

António Gama esteve envolvido, nos anos 80, em dois principais projetos: "Tempos livres - Leiria", coordenado por Jorge Gaspar (CEG Lisboa, 1981) e "O estado, a economia e a reprodução social na semi-periferia do sistema mundial: o caso português", coordenado por Boaventura Sousa Santos (CES-JNICT, 1987-1991). Se no âmbito deste ultimo projeto havia de publicar "Espaço e Sociedade numa Situação de Crescimento Urbano Difuso” (Boaventura de Sousa

1 http://www.ces.uc.pt/milton_santos/pages/pt/apresentacao.php 
Santos (org.; 1993), Portugal: Um Retrato Singular: 439-473), enquanto investigador do Centro de Estudos Sociais publicou na Revista Crítica, entre 1981 e 1992, diversos artigos: "Análise espacial de uma transformação da agricultura" (com Graça Santos e Iva Pires; n.o 7/8, 1981); "Uma Ruptura Epistemológica na Geografia - A Teoria dos Lugares Centrais" (No 12, 1983); "Indústria e Produção de um espaço Peri-urbano" (n.o 22, 1987); “Urbanização Difusa e Territorialidade Local" (n. $\left.{ }^{\circ} 34,1992\right)$.

Envolve-se, fundamentalmente depois dos anos de 90, em diversos projetos desenvolvidos com colegas do Departamento de Geografia de que se destacam: (i) "A bacia hidrográfica do rio Lis - Contributo para o estudo da organização do espaço e dos problemas do ambiente" (1989); (ii) "Dinâmicas Sócio-económicas e (Re)organização Territorial: processos de Urbanização e de Reestruturação Produtiva" (Projecto Estímulo para as Ciências Humanas - JNICT/IEG; 1992 -1994), coordenado por José Manuel Pereira de Oliveira, no âmbito do qual, entre outros contributos, publicou no livro do seminário de encerramento do projeto um artigo sobre "Processos Sociais e Urbanizaçâo"; (iii) anos mais tarde, integrado no evento "Coimbra Capital Europeia da Cultura" e no Projeto "Coimbra e Território - Coimbra, o País e o Mundo", foi coorganizador de três publicaçóes: "Fragmentos de um retrato inacabado - A geografia de Coimbra e as metamorfoses de um país" (2003); “Olhar o mundo ler o território" (2004); "Esta Coimbra - Alfredo Fernandes Martins, A Cidade e o Cidadão" (2006).

Passou a colaborar, posteriormente, com o Centro de Estudos Ibéricos, em atividades e eventos regulares, onde acabou por publicar algumas das suas intervençôes em ediçôes do CEI: "Água, uma questão geopolítica" (2006), "Porém as coisas de que falam as fábulas já não se encontram mais" (2008), "Cidade, moderna urbanização e novas lógicas de organização espacial" (2012) e "As cidades e os processos de urbanização" (2013).

Este breve olhar sobre uma obra multifacetada, com perímetro irregular e sem fronteiras definidas, além do ritmo irregular, mostra algumas metamorfoses temáticas verificadas desde a fase "de juventude", quando as suas preocupaçóes ainda estavam centradas na geografia física. É a geomorfologia, a inquietude e a avidez de mudança que vão inspirar, inicialmente, a grande 
rutura, temática e epistemológica, que o hão-de levar a uma progressiva aproximação das ciências sociais. Os anos 80 e 90, vividos sob o espetro da tese, entre indecisão e incertezas, foram de amadurecimento da investigação própria e partilhada, sem que, para António Gama, a geografia deixasse de ser uma paixão ou razão para melhor compreender o mundo e nele intervir.

É isso que encontramos na sua obra, publicada e verbalizada, fragmentos que apontam para as coordenadas que estruturam o seu pensamento e balizaram a sua prática.

\section{Coordenadas de uma obra: breve roteiro para uma viagem}

"Esta rutura gera-se relativamente às tendências naturalistas e historicista, até então praticadas na geografia. Ao mesmo tempo que adopta um posicionamento teórico-metodológico de tipo hipotético-dedutivo e, por isso, nomotético, isto é, procurando leis, toma como ponto de partida a atribuição à geografia humana do estatuto de ciência social, como ciência do espirito" (AG, 1983).

Os temas nucleares abordados nos textos publicados por António Gama ao longo de quatro décadas esboçam uma cartografia que tem por linhas estruturantes a Geografia Física, a Teoria da Geografia, a História da Geografia, a Geografia Cultural, a Geografia Social, a Geografia Económica, a Geografia Politica e a Geografia Urbana. São temas nucleares que tanto correspondem a cursos que lecionou como áreas de investigação, coordenadas que nos podem orientar numa viagem pelo tempo e pelos espaços duma obra ampla e diversa.

\section{a) Geomorfologia}

"E a sedução vem tanto no plano metodológico, na confrontação duma teoria como uma prática, como no epistemológico, numa exegese de prática-teoria na 
busca de rigor no discurso em geomorfologia, ao enfrentar um tema em que as formas de erosão e as formas de acumulação quaternária estão interdependentes e toma uma amplitude paralela no conjunto da problemática" (AG, 1974).

A posição da geomorfologia entre a geologia e a geografia coloca-a perante um problema de identidade que António Gama problematizou desde a tese de licenciatura. Se tal parceria permitiu cruzar diferentes temas e enriquecer a explicação das formas da superfície da terra desde os fundadores da geomorfologia, a partir da teoria do ciclo da erosáo (William Morris Davis) e do movimento renovador da geomorfologia após a segunda guerra mundial as abordagens geossistémica haviam de aumentar o grau de complexidade. Desde "A Morfologia dos Tufos de Condeixa" (1974), posteriormente retomada nos Cadernos de Geografia (1984), nunca perdeu de vista a "Épistémologie de la Géomorphologie" (Alain Reynaud, 1971), debate que havia de encerrar em "Geomorfologia: a construção de uma identidade" (2013), numa parceria com Luca A. Dimuccio, assim rematado: "O estudo histórico da posição da Geomorfologia" na partilha académica pode ser vista sob duas perspectivas distintas: uma que aborda a história do seu desenvolvimento, cruzando-a com um olhar epistemológico em cada fase de desenvolvimento; outra que procura contextualizar essa história com os processos de partilha disciplinar na organizaçáo dos estudos em países com diferentes tradiçóes académicas. Uma e outra via contribuem para aclarar a razáo do surgimento de temas de estudo específicos, da elaboração de linguagens e da adoção de métodos" (AG, 2013: 780).

b) Teoria da Geografia

"A importancia desta ruptura assinala-se também pelo seu significado no pensamento geográfico, que se traduziu na afirmaçâo da geografia como ciência social, assumida pelos desenvolvimentos dos estudos geográficos a partir da teoria dos lugares centrais. A sua reavaliação deverá ser feita tendo em conta principalmente os aspetos metodológicos” (AG, 1983). 
As suas preocupaçóes sobre os contextos teóricos em que assentam os alicerces da geografia, embora anteriores, acentuam-se quando explicita a rutura com a geografia física e a "geografia tradicional", entâo hegemónica, patente no primeiro artigo que deu à estampa: "Algumas notas sobre as relaçôes entre a Geografia e as Ciências Sociais" (Biblos, 1977). O texto pode ser visto como um manifesto, qual programa para uma vida, linha de reflexão e de investigação que havia de desdobrar, ao longo dos anos, em outras abordagens, designadamente "Racionalidade económica e Teoria Geográfica" (1980), "Uma ruptura epistemológica na geografia: a teoria dos lugares centrais" (1983), "Escalas, Representação e Acção Social" (1998) ou "Uma revisitação à time space geography: A geografia do tempo e a teoria social" (2007). Estes textos são percorridos pela ideia de "assinalar-se o significado da rutura teórica", de discutir ou precisar conceitos, como acontece em dois casos paradigmáticos que se adiantam: (i) "A escala é, antes de mais, uma relação entre a realidade e a sua interpretaçáo, e, assim, tanto pode ser a transiçáo de uma certa porçáo de espaço num mapa, como um nível de análise a ter em conta quando se quer representar a espacializaçáo de um determinado fenómeno. (...) qualquer mudança de escala modifica, de uma maneira geral, as percepçóes e as representaçōes e, por vezes, mesmo a natureza dos fenómenos. É, então, a partir daí uma questão de relação entre sujeito e objecto e, sobretudo, uma questáo de descontinuidades na ordem particular dos fenómenos, dado que os objetos já não têm a mesma significação nem a mesma estrutura. (...) A questão da diferenciação em campos analíticos distintos entre o indivíduo e a sociedade, entre o micro e o macro ou o local e o global, deixa de ter o mesmo sentido, porque cada vez mais estas questóes são vistas de um modo em que se privilegiam as interrelaçóes, recorrendo a conceitos mediadores" (AG, 1998); (ii) "A geografia do tempo de Hagerstrand pelas suas potencialidades de abertura às outras ciências sociais veio dar uma importante contribuição para o desenvolvimento da teoria social, nomeadamente, na constituiçấo da teoria da estruturação. (...) A teoria da estruturação surge do estado das ciências sociais separadas por um dualismo, a tal ponto que se podiam falar de duas sociologias, duas antropológicas, duas geografias, com bases semelhantes, em correspondência com o dualismo básico da experiência 
maioria moderna. Em suma, uma via envolvendo as estruturas, as relaçôes estruturais e sistémicas; outra, cuja atenção é dada aos indivíduos, às práticas individuais e às relações interpessoais" (AG, 2007).

\section{c) História da Geografia}

"São mais os fatores sociais que explicam a institucionalização e a aparição duma comunidade cientifica de geógrafos, assim como são eles que explicam muitas das caracteristicas que a ciência adoptou, nomeadamente a sua situação na Universidade" (AG, 2011).

Os estudos que realizou em torno deste tema viram a luz do dia, na forma escrita, em três momentos fundamentais: (i) por altura do Primeiro Colóquio Ibérico de Geografia onde publicou, com Jorge Gaspar, "Perspectivas da Geografia Humana em Portugal. Ensino, investigaçâo e carreiras" (1979); (ii) no âmbito do Projeto "Coimbra e Território - Coimbra, o País e o Mundo", lançado com o objetivo de efetuar uma retrospetiva da Evolução da Geografia de Coimbra e homenagear um dos seus Mestres, o Professor Alfredo Fernandes Martins, coorganizou "Fragmentos de um retrato inacabado - A geografia de Coimbra e as metamorfoses de um pais" (2003) e "Alfredo Fernandes Martins, geógrafo de Coimbra, cidadão do Mundo" (2006); (iii) retoma o tema ao publicar "Geografia e Geógrafos: Institucionalização e consolidação da Geografia na Universidade de Coimbra” (2011), num artigo preparado, a convite de Fernando Catroga. para o livro comemorativo do Centenário da Faculdade de Letras da Universidade de Coimbra.

\section{d) Geografia Cultural}

"As imagens desse vivido quotidiano expressam-se nas maneiras de estar: da pose dos corpos ao vestuário, dos gestos aos objetos. Das maneiras de estar 
falam-nos a pose dos corpos e os gestos de mãos, os caminhares apressados pela rua, contrastado com o parado dos velhos a conversar sentados nuns degraus. O vestuário mostra-nos em claro-escuro a diferenciação de gerações, contrapondo à regra da tradição, a novidade e a diferença, trazida por alguns feirantes ou numa compra na cidade" (AG, 2008).

Os temas de geografia cultural a que deu mais atenção partiram da leitura atenta da obra de Orlando Ribeiro e do potencial que encerra para interpretar o país e das civilização com que dialoga, designadamente a mediterrânica, aspetos que se encontram plasmados em títulos como "Geografia e Civilização - A propósito da obra de Orlando Ribeiro" (1981), “Os sentidos de mediterrâneo e a geografia portuguesa" (1990) e "As tradiçóes do pão, território e desenvolvimento" (com Norberto Santos; 2011). Podemos enquadrar ainda neste âmbito "O Espaço na Revolução Republicana de 1910" (1985), "Porém as coisas de que falam as fábulas já não se encontram mais" (2008) ou a breve nota introdutória ao livro Portugal Visto do Céu, em que discorreu sobre "o prazer de ver a paisagem" (2008).

e) Geografia social

"A relação espaço-tempo evidência, nas sociedades modernas, no que concerne às actividades de ócio, situações onde se entrecruzam toda uma série de elementos, da organizaçấo social às formas ideológicas. Tempo de trabalho e tempo livre, formas de comunicação social, valores culturais e os tempos da moda expressam-se nos usos do espaço" (AG, 1988).

Entre outros trabalhos que se podiam inventariar neste apartado destacam-se os relacionados com o ócio e os tempos livres porque António Gama foi um dos pioneiros nos estudos sobre a geografia do lazer. Entendia, como Dumazedier, que o ócio se define a partir do descanso, do divertimento e do desenvolvimento (três D's), relevando e entendendo a evasão/compensação 
“como fuga imaginária ou efetiva da realidade da vida", sempre constrangedora e penosa, em que um dos contrapontos é o passeio no campo, ócio físico e ativo que enaltece o convívio com os espaços livres (AG, 1992; 2008). Com Jorge Gaspar, João Ferrão e Fernando Honório começou por publicar "Utilização dos tempos livres. Concelho de Leiria: Caracterização socio-económica e equipamentos colectivos" (1981) a que se seguiu "O Espaço, o Tempo e o Ócio - Notas para uma Geografia do tempo Livre” (1988). Com Norberto Santos publicou, nos anos 90, "Tempo Livre, Terciário e Lazer" (1991), "Espaços de Sociabilidade" (1997), "Os espaços/tempos de lazer na sociedade de consumo contemporânea" (1999) e "O Tempo de Consumo e os Espaços de Lazer" (2000). $\mathrm{O}$ investimento de décadas nestas matérias, que havia permanecido inédito, como aconteceu com muitos outros escritos, acabam por ser publicados na antologia que coorganizou "Lazer. Da libertação do tempo à conquista das práticas" (Imprensa da Universidade, 2008), onde lançou "Fundamentos para uma geografia do tempo livre" e "Associativismo e práticas de ócio", escritos em 1992 e 1994, respetivamente, preparados inicialmente como textos de apoio para os alunos de Geografia e Turismo, Lazer e Património, curso que estava a dar os primeiros passos no Departamento de Geografia de Coimbra. A bibliografia citada nestes textos reflete os seus autores diletos, que mais contribuíram para formar o seu pensamento sobre a Geografia do Tempo Livre, onde convivem os modernos, que haviam publicado mais recentemente, com os clássicos. Recupera uma certa herança libertária da geografia quando inclui, por exemplo, "O Direito à Preguiça", publicado por Paul Lafargue, em 1880, no jornal socialista L'Égalité, onde polemiza as visóes liberais, conservadores e até marxistas do trabalho, citado a partir da versão francesa, de 1965, editada pela Maspero.

\section{f) Geografia Económica}

"Este espaço não deixa, no entanto, de ser polarizado pela cidade, na organização espacial das actividades económicas, no domínio das trocas e da gestão 
empresarial e financeira. Nele, coexistem aspetos rurais e urbanos que se traduzem na plurifuncionalidade do uso do solo, na pluriatividade das suas populaçóes e na complexidade da estrutura social e das práticas culturais. A plurifuncionalidade e a pluriatividade, como consequência dos novos modos de comunicar e fazer, tornam-se características definidoras da peri-urbanização” (AG, 1987).

Os estudos que publicou abordam temas (socio)económicos que visam contextualizar as problemáticas prevalecentes nas áreas onde fez investigação empírica, que são, fundamentalmente, os espaços peri-urbanos e de urbanização difusa. Nuns casos tentou compreender como a evolução e a especialização da economia influenciou a (re)organização do espaço, como acontece em "Análise espacial de uma transformação da agricultura" (com Iva Pires e Graça Santos; 1981). Noutros, a preocupação é avaliar a interferência das mudanças económicas nas transformaçôes sociais, onde se destacam dois títulos principais: "Indústria e produção de um espaço peri-urbano" (1987), e "Dinâmicas locais da Pequena Industria" (com Norberto Santos e Nuno Serra; 1992). No primeiro caso adiantou que devemos "considerar o território como um espaço produzido pelas relaçóes sociais, mas também produtor de relaçôes sociais, tem como consequências atribuir ao espaço uma importância, como condicionador de relaçóes sociais (distancia, factores naturais, implantaçóes humanas). No entanto, este papel condicionador deve ser examinado de forma relativa com os modos de organização social, tendo em conta que os limiares técnicos são ao mesmo tempo limiares sociais" (AG, 1987). O debate passa, noutros casos, por compreender os sistemas produtivos locais, a "urbanização" de determinados espaços rurais, entrando na discussão das relaçóes entre capital social e desenvolvimento territorial, em distintos contextos regionais, partindo do conceito de "Terceira Itália", em voga nos anos 80, difundido, entre outros, por Becattini, Fuà, Zacchia e Bagnasco. Debruçou-se ainda sobre os processos de desenvolvimento regional e local e os seus reflexos em termos ambientais e de ordenamento do território em "A bacia hidrográfica do rio Lis - Contributo para o estudo da organização do espaço e dos problemas do ambiente" (em colaboração com vários colegas; 1989) e "Fronteiras, fracturas 
e reestruturação do território: processos de marginalização e transformaçóes do rural e do urbano na Regiâo Centro" (com Rui Jacinto; 2002).

\section{g) Geografia Política}

"Houve tempo em que a água era considerada genericamente um bem livre. (...) A água, como qualquer recurso, tornou-se por consequência fulcro das relaçóes de poder e geradora de conflitos, tornando o seu controlo e a sua posse, seja de rios, lagos, ou reservas subterrâneas, uma questão fundamentalmente política, e, portanto, de geopolitica" (AG, 2006).

António Gama sempre acompanhou de perto os temas de geografia politica e da geopolítica, como leitor compulsivo de jornais e de revistas ou através de leituras e reflexôes preparatórias das cadeiras que ministrou com este titulo. Os seus artigos repartem-se entre "O Território como inscrição do Poder" (1988), ou "A água: uma questão geopolítica” (2006), passando pelo debate sobre a capitalidade e o pano de fundo subjacente aos processos de globalização que acontece nestes dois casos: "As Capitais no discurso geográfico" (1994), e "Ascensáo e Queda das Rotas de Mar" (1999), A centralidade natural adquirida pela generalidade das capitais acaba por "agir sobre o território a que estendem a sua dominação", decorre tanto do campo socio-cultural como do reforço dos sistemas sémicos (a língua, a cultura e a informação) (AG, 1994,. No caso da ascensão e queda das rotas de mar destaca que "desde a revolução industrial, e por fases distintas, o peso dos diversos circuitos de mercadorias foi mudando, alterando-se com eles a geografia das rotas de transportes marítimos. (...) Desde à meio século, o circuito tradicional Norte-Sul, de troca de manufaturas por produtos primários, que imperou durante a primeira metade do século, foi cedendo a primazia ao tráfico tradicional Este-Oeste, de produtos manufaturados entre países industriais. Assim, actualmente, o quinhão mais importante do comércio internacional tem origem e destino nos países desenvolvidos (AG, 1999).” 
h) Geografia Urbana

"A cidade aparece assim, desde a sua origem, como um lugar emblemático de poder. Poder que se inscreve sobre os corpos e sobre os espaços de modo a organizar as populaçóes e os recursos que fazem parte dos territórios e dos quais são artífices. A cidade, surge por isso como uma obra humana, marcada numa primeira análise como um regulador económico das pessoas e das riquezas" (AG, 2012).

Os temas relacionados com a geografia urbana, por forças das circunstâncias, foram onde mais investiu, percorrendo as problemáticas sociais, económicas e políticas para melhor interpretar as dinâmicas urbanas e territoriais, tanto a nível local como regional. Os escritos sobre a cidade e os processos de urbanização, sobre o urbano e seus paradoxos, obedecem a um discurso onde a cidade é a expressão máxima do poder e do controlo sobre o território, interpretação que abordou a partir de três principais direçóes: (i) o planeamento regional e urbano, comentado em textos como "Os Planos de Urbanização e o Crescimento Urbano: as Linguagens $e$ as Práticas - A propósito dos planos de urbanização de Coimbra" (1982), e "Urbanização e Planeamento - Do Poder da Razáo às Razóes do Poder" (1986); (ii) análise das dinâmicas do crescimento urbano difuso, típico de algumas áreas do litoral centro e norte do Continente, designadamente do eixo Leiria-Marinha Grande que estudou com profundidade, problemáticas que encontramos em "Urbanização Difusa e Territorialidade Local" (1992), "Processos Sociais e Urbanização" (1996), "Urbanização, esfera doméstica e relaçôes residência-trabalho" (com Norberto Santos e Nuno Serra; 1993), ou "Espaço e Sociedade numa Situação de Crescimento Urbano Difuso" (1993). Neste último artigo mostra como "os espaços de vida constituem espaços sociais que se apresentam, ao mesmo tempo, segmentados em unidades territoriais elementares com características próprias geradas pelas redes informais locais, constituindo um tipo de comunidade protegida, em que as redes de sociabilidade e a espacialidade de vizinhança (o bairro, a aldeia urbanizada) se identificam fortemente" (AG, 1993); (iii) em outras abordagens discute a cidade, a rede urbana e novos modos de organização espacial, designadamente em "Petites villes et urbanization au 
Portugal" (1994), "Cidade, moderna urbanização e novas lógicas de organização espacial" (2012), ou "As cidades e os processos de urbanização" (2013), onde afirma que "os espaços sociais e económicos que constituem as cidades estão atravessados por contradiçôes e conflitos de apropriação. De utilização e de avaliação que os grupos sociais fazem do espaço e que se expressam na segregação dos usos, nas formas residenciais e nos diferentes tipos de desigualdades sociais. À nova ordem social também corresponderá uma ordem espacial, medida ou imposta pelos poderes instituídos e organizadores dessa ordem, com configuraçóes de geometria variável“ (AG, 2013).

A breve digressão que acabamos de fazer evidencia, além do empenho, capacidade de diálogo e abertura a outras ciências sociais, o lado inovador das abordagens teóricas e metodológicas induzidas, contributos relevantes do António Gama para o processo de viragem verificado na Geografia portuguesa depois de 1974. Há que juntar à importância do seu legado, a atualidade e a validade da sua mensagem: a necessidade de termos uma geografia comprometida, crítica, aberta, sem fronteiras nem perímetro definido, disponível para ter um papel direto na ação, isto é, ter um envolvimento ativo na prossecução da tão propalada coesão económica, social e territorial. Acreditava que a literacia geográfica era indispensável para formar uma cidadania consciente, mas, fundamentalmente, formar uma cultura territorial que impregnasse e influenciasse positivamente políticas públicas mais solidárias e inclusivas.

Em tempos líquidos como os que vivemos, marcados pela insustentável leveza dum saber plano que continua a proliferar, faz ainda mais falta a voz lúcida e informada do António Gama. Faz falta o seu conselho assertivo, a informação enciclopédica sobre autores e bibliografias, as opiniôes críticas, livres, descomprometidas, sem amarras, fora da caixa, que nos obrigavam a olhar para o mesmo problema com um novo olhar e sob outras perspetivas.

Qual formiga no carreiro, o António Gama era encontrado tantas vezes em sentido contrário; contudo, embora andasse quase sempre em contramáo, nunca atrapalhou o tráfego. 


\section{Bibliografia}

As citaçôes foram transcritas dos seguintes textos de António Gama:

Gama, António (1974). A Morfologia dos Tufos de Condeixa, policopiado.

Uma ruptura epistemológica na geografia: a teoria dos lugares centrais. (1983) Revista Critica de Ciências Sociais, 12, 1983, 41-59.

Indústria e produção de um espaço peri-urbano. Revista Crítica de Ciências Sociais, 22, 1987, 33-54.

O Espaço, o Tempo e o Ócio - Notas para uma Geografia do tempo Livre. Cadernos de Geografia, 7 , 1988 (Republicado em Lazer. Da libertação do tempo à conquista das práticas: 17-28).

Espaço e Sociedade numa Situação de Crescimento Urbano Difuso. in Boaventura de Sousa Santos (Org.; 1993), Portugal: Um Retrato Singular. Porto: Afrontamento, 439-473.

As Capitais no discurso geográfico. Penélope, 13, 1994: 9-21.

Processos Sociais e Urbanização. in J. M. Pereira de Oliveira et al. (Org.; 1996), Dinâmicas Sócio-económicas e Reorganização Territorial: processos de Urbanização e de Reestruturação Produtiva. Coimbra: Instituto de Estudos Geográficos da F.L.U.C: 409-434.

Escalas, Representação e Acção Social. Cadernos de Geografia, 17, 1998.

Ascensão e Queda das Rotas de Mar. Notícias do Milénio, Ed. do Diário de Notícias, Junho de 1999.

Água, uma questäo geopolítica. in Rui Jacinto et al. (Coord.; 2006) - O interior raiano do Centro de Portugal. Outras fronteiras, novos intercâmbios. CEI, Iberografias, 8: 43-59.

Uma revisitação à time space geography: A geografia do tempo e a teoria social. in AA.VV. (org.; 2007), Geophilia. O Sentir e os Sentidos da Geografia. Lisboa: Centro de Estudos Geográficos: $90-113$.

Fundamentos para uma geografia do tempo livre. in Santos, Norberto e Gama, António (Org.; 2008) - Lazer. Da libertação do tempo à conquista das práticas. Coimbra, Imprensa da Universidade: $85-106$.

Porém as coisas de que falam as fábulas já não se encontram mais. (2008). in Jacinto, Rui (Org.; 2008), Transversalidades. Territórios, Diálogos e Itinerários Ibéricos. Guarda, Centro de Estudos Ibéricos: 67-71.

Geografia e Geógrafos: Institucionalização e consolidação da Geografia na Universidade de Coimbra. (2011). Biblos, vol. Ix, (2.a série): 217-246.

Cidade, moderna urbanização e novas lógicas de organizaçäo espacial. in Jacinto, Rui (Coord.; 2012) - A cidade e os novos desafios urbanos. Guarda, CEI, Iberografias (20), 83-94.

As cidades e os processos de urbanização. in Jacinto, Rui (Coord.; 2013), Transversalidades. Fotografia sem fronteiras. Guarda, Centro de Estudos Ibéricos: 133-135.

Cabero Dieguez, Valentin (2016) - António Gama y el viaje: un géografo con una mirada abierta, sin fronteras. Iberografia (11), CEI.

Ferrão, João (2015) - António Gama: um geógrafo peculiar. Finisterra (99), CEG Lisboa.

Gaspar, Jorge (2015) - António Gama ou uma "certa tradição geográfica". Finisterra (99), CEG Lisboa. 
Jacinto, Rui; Cravidão, Fernanda, Campar, António; Santos Norberto, Cunha, Lúcio (2015) Gama Mendes, António, Um geógrafo inquieto, um heterodoxo inconformado. Finisterra (99), CEG Lisboa.

Jacinto, Rui (2016) - Viagem nunca feita: desenhar o mapa do mundo desconhecido. Iberografia (11), CEI. 